changes in proteinuria ${ }^{12}$. It is noteworthy that mice in general have strain-dependent responses to proteinuria and are likely to be more resistant to developing higher level of proteinuria in comparison to humans, for example, during diabetic nephropathy ${ }^{13}$. The reasons for differences in proteinuria and renal disease progression between mice and humans are presently not completely understood $^{14}$. From a clinical standpoint, however, the levels of proteinuria that can be achieved in mouse models are sufficient to study disease mechanisms, especially in a time when knowledge about the relationship of proteinuria and disease progression has changed so that clinicians also worry about low levels of proteinuria. Clinicians even recommend treatment for individuals with very low levels of urinary protein loss that are at increased risk for renal and cardiovascular disease ${ }^{15}$.

4. The validation of the LPS model by independent investigators makes it a more applicable, and growing, tool in glomerular research $^{16-18}$.

5. Key effectors of the LPS model, that is, B7- $1^{8}$, cathepsin $\mathrm{L}^{9}$ and urokinase-type plasminogen activator receptor ${ }^{1}$, have been detected in podocytes in vivo and are induced during human proteinuric kidney diseases.

Regarding the second question of Dr. Comper, there is not much else to offer at this point other than that we did not study albumin filtration directly in the LPS model or any other of our mouse models, nor do we know of any studies where this has been done. Although such studies would probably be of value, they are currently techni- cally very difficult and harbor high risk of erroneous analysis. More importantly, it is very well established that the glomerular capillaries function as the filtration barrier that retains albumin and other plasma proteins in the circulation ${ }^{19,20}$.

\section{Jochen Reiser \& Peter Mundel}

Division of Nephrology and Hypertension, University of Miami Miller School of Medicine, 1580 Northwest Tenth Avenue, Batchelor Building, Sixth Floor, Miami, Florida 33136, USA.

e-mail: jreiser@med.miami.edu or pmundel@med.miami.edu

1. Wei, C. et al. Nat. Med. 14, 55-63 (2007).

2. Faul, C. et al. Nat. Med. 14, 931-938 (2008).

3. Oliver, W.J. \& Kelsch, R.C. Endocrinology 75, 973-974 (1964).

4. Seiler, M.W., Venkatachalam, M.A. \& Cotran, R.S. Science 189, 390-393 (1975).

5. Asanuma, K. et al. J. Clin. Invest. 115, 1188-1198 (2005).

6. Pacquement, H. et al. Arch. Fr. Pediatr. 46, 741-742 (1989).

7. De Gaudio, A.R., Adembri, C., Grechi, S. \& Novelli, G.P. Intensive Care Med. 26 1364-1368 (2000).

8. Reiser, J. et al. J. Clin. Invest. 113, 1390-1397 (2004).

9. Sever, S. et al. J. Clin. Invest. 117, 2095-2104 (2007).

10. Zhao, H.J. et al. J. Am. Soc. Nephrol. 17, 2664-2669 (2006).

11. Möller, C.C. et al. J. Am. Soc. Nephrol. 18, 29-36 (2007).

12. Nakagawa, T. et al. J. Am. Soc. Nephrol. 18, 539-550 (2007).

13. Quaggin, S.E. \& Coffman, T.M. J. Am. Soc. Nephrol. 18, 364-366 (2007)

14. Breyer, M.D. et al. J. Am. Soc. Nephrol. 16, $27-45$ (2005).

15. Ruggenenti, P. \& Remuzzi, G. Kidney Int. 70, 1214-1222 (2006).

16. Peters, I. et al. J. Am. Soc. Nephrol. 17, 1644-1656 (2006).

17. Lorenzen, J. et al. J. Am. Soc. Nephrol. 19, 884-890 (2008)

18. Sun, Y. et al. Am. J. Nephrol. 29, 558-570 (2009).

19. Farquhar, M.G. J. Clin. Invest. 116, 2090-2093 (2006).

20. Tryggvason, K., Patrakka, J. \& Wartiovaara, J. N. Engl. J. Med. 354, 1387-1401 (2006).

\title{
Disease mongering is a myth
}

\section{To the Editor:}

Your article 'Straight Talk with Ray Moynihan'1 indulges the myth that the pharmaceutical industry invents diseases. As a 30-year veteran of pharma research and development, I can categorically state that this is false.

Is 'bone thinning' a disease? No. However, for a petite woman of Asian or Northern European descent, bone thinning as measured by bone mineral density scans is the first sign of osteoporosis. Should one wait until such a person has a serious fracture before starting treatment with a medicine that can slow the progression of bone erosion?

Hypercholesterolemia also isn't a disease. However, if one is an overweight male smoker with a family history of heart disease and high lowdensity lipoprotein cholesterol, you are at high risk of a heart attack or stroke. The first steps for treating such a person must be diet and exercise. However, often this isn't sufficient, and statin treatment is necessary.
Treatment of bone thinning or hypercholesterolemia is not 'disease mongering' - it is preventative medicine. Furthermore, drug treatment to prevent hip fractures and heart attacks and strokes, which are extremely costly to the healthcare system, is not just good for people at risk, it also makes good economic sense.

\section{COMPETING INTERESTS STATEMENT}

The author declares competing financial interests: details accompany the full-text HTML version of the paper at http://www.nature.com/naturemedicine/.

\section{John L LaMattina}

Former President of Pfizer Global Research and Development, 127 Wamphassuc Point Road, Stonington, Connecticut 06378, USA. e-mail: john.lamattina@comcast.net

1. Nat. Med. 14, 1142-1143 (2008). 